\title{
The Effect of Autologous Platelet Rich Plasma in the Treatment of Achilles Tendon Ruptures: An Experimental Study on Rabbits
}

\author{
Baran Şen ${ }^{1}$, Serkan Güler ${ }^{1}$, Berivan Çeçęn ${ }^{2}$, Erdem Kumtepe ${ }^{2}$, Alper Bağrıyanık ${ }^{3}$, Sermin Özkal ${ }^{4}$, \\ M. Ali Özcan ${ }^{5}$, Hayri Özsan ${ }^{5}$, Namık Şanl1 ${ }^{5}$, M. Hasan Tatari ${ }^{1}$ \\ ${ }^{1}$ Department of Orthopaedics and Traumatology, Dokuz Eylül University Faculty of Medicine, İzmir, Turkey \\ ${ }^{2}$ Department of Biomechanics, Dokuz Eylül University Institute of Health Science, İzmir, Turkey \\ ${ }^{3}$ Department of Histology and Embriology, Dokuz Eylül University Faculty of Medicine, İzmir, Turkey \\ ${ }^{4}$ Department of Pathology, Dokuz Eylül University Faculty of Medicine, İzmir, Turkey \\ ${ }^{5}$ Department of Hematology, Dokuz Eylül University Faculty of Medicine, İzmir, Turkey
}

Background: Achilles tendon ruptures are characterized by a long recovery period, high re-rupture rate and late return to work. To overcome these difficulties and augment tendon repair, many agents have been used.

Aims: To determine the effect of autologous platelet rich plasma (PRP) in the treatment of Achilles tendon ruptures in rabbits.

Study Design: Animal experimentation.

Methods: The study included 14 New Zealand albino rabbits that were divided randomly into 2 groups, $\mathrm{A}$ and $\mathrm{B}$, each containing seven rabbits. On day zero, all 28 Achilles tendons were tenotomized and repaired. In group $A$, the tendons were injected with PRP post-surgery, whereas those in group B were left untreated. On day 28, the right tendons in both groups were examined histopathologically via both light and electron microscopy, and the left tendons were subjected to biomechanical testing.
Results: The histological and biomechanical findings in both light and electron microscopy in group A were better than those in group $\mathrm{B}$, but the difference was not significant. According to Tang's scale, the mean value in Group A was 3.57, while it was 3.0 in Group B. The mean value of Group A for the length of collagen bands was $48.09 \mathrm{~nm}$ while the mean value of Group B was $46.58 \mathrm{~nm}(\mathrm{p}=0.406)$. In biomechanical tests, although stiffness values were higher in group A, the difference between groups was not significant. In addition, maximum load values did not differ between groups A and B.

Conclusion: PRP had no effect on the healing process 28 days post-Achilles tendon rupture.

Keywords: Achilles tendon, electron microscopy, platelet-rich plasma, tendon healing, tendon rupture
Achilles tendon ruptures are characterized by a long recovery period, high re-rupture rate and late return to work (1-3). Treated either conservatively or surgically, some patients may present with re-ruptures during the late phases of healing, generally between the $4^{\text {th }}$ and $12^{\text {th }}$ weeks $(1,4)$, especially when the tissue quality is poor. As such, some biochemical agents including hyaluronic acid (5), calcitonin (6) and butyric acid (7), and various biomaterials, such as amniotic membrane and fluid (8), porcine intestinal submucosa $(9,10)$, porcine dermal patch (11-13) and human dermal tissue matrix (14) have been used to augment tendon repair.

Researchers have recently exhibited interest in growth factors that were shown to have positive effects on tendon healing (15-19) via acting on target cells present at the site of injury (1). Many studies have reported that autologous platelet-richplasma (PRP), derived from a patient's venous blood, includes

This study was presented at the $12^{\text {th }}$ Turkish Society of Sports Traumatology Arthroscopy and Knee Surgery Congress, 23-27 September 2014, Izmir, Turkey. Address for Correspondence: Dr. M. Hasan Tatari, Department of Orthopaedics and Traumatology, Dokuz Eylül University Faculty of Medicine, İzmir, Turkey Phone: +905323446041 e-mail: hasan.tatari@deu.edu.tr

Received: 25.06.2014 Accepted: 03.06.2015 - DOI: 10.5152/balkanmedj.2015.15549

Available at www.balkanmedicaljournal.org 
a mixture of growth factors (20-22) and can be used to treat tendon injuries as well as other sports-related disorders, and enhance cellular response to injury (20-22) and angiogenesis (23), despite the lack of evidence-based findings. However, the number of animal studies $(1,24-28)$ that have reported both histopathological and biomechanical findings post-administration of PRP to the Achilles tendon and the number of human trials (3,29-32) are insufficient.

As such, the present experimental study aimed to determine the histopathological and biomechanical effects of autologous PRP on the treatment of Achilles tendon rupture.

\section{MATERIALS AND METHODS}

The study protocol was approved by the Local Animal Research Ethics Committee. Following sample dimension analysis, the experiment was performed using 28 Achilles tendons from 14 adult male New Zealand albino rabbits at the Local Research Center. The mean weight of the rabbits was 3520 (range, 2800 to 4200) grams.

\section{PRP preparation, pilot study}

To prepare PRP, a pilot study was performed using two rabbits and the method described by Yokota (33). Blood (10 cc) was obtained from the ear vein of each rabbit; however, because the optimum platelet concentration could not be achieved, the samples were centrifuged for a second time at $2500 \mathrm{rpm}$ for five minutes, as described by Efeoglu et al. (34). The upper limit of the automatic hematology apparatus used to determine the platelet count was $1 \times 10^{6} \mathrm{~mL}$; therefore, PRP was diluted 4-fold to measure the platelet count. When the rabbit platelet concentration increased 3.5-fold, it was selected for use in the study.

\section{Blood collection and PRP preparation}

Blood samples were obtained from the ear vein of all 14 rabbits after the left ear of each was shaved and cleaned with xylol. Blood $(10 \mathrm{cc})$ was collected into EDTA Vacutainer tubes and $0.5 \mathrm{cc}$ of blood was collected into pediatric EDTA Vacutainer tubes via a $24 \mathrm{G}$ catheter. Blood in the pediatric tubes was used to measure the platelet counts, whereas the larger tubes, following 5-minute centrifugation, were sent via cold chain to the hematology laboratory to prepare PRP.

Blood samples were first centrifuged at $1500 \mathrm{rpm}$ for ten minutes, and the plasma at the upper level was removed with the buffy coat and separated from the red blood cells. Then, the sample was centrifuged again at $2000 \mathrm{rpm}$ for ten minutes to separate the platelet-poor part in the upper level. The remain- ing sample was centrifuged again at $2500 \mathrm{rpm}$ for ten minutes and the lower third (approximately $1.5 \mathrm{cc}$ ) was considered to be PRP. After adding $0.5 \mathrm{~mL}$ of calcium chloride $\left(\mathrm{CaCl}_{2}\right)$ to PRP for activation, $200 \mu \mathrm{L}$ was removed from each PRP sample and the platelet count was measured after 4-fold dilution. PRP was then transported to the surgical suite via cold chain.

The platelet count in the blood samples and in PRP were measured and evaluated statistically via the non-parametric Mann-Whitney $U$ test (Table 1) and the difference between two groups, regarding the beginning and injection-time values separately, was not significant $(p>0.05)$. In both groups, the platelet count increased about 3.5-fold.

\section{Operative procedure}

On day zero, the operative procedure was performed under general anesthesia induced via IM injection of ketamine 40 $\mathrm{mg} / \mathrm{kg}$ (Ketalar, Eczacıbaşı; İstanbul, Turkey) ten minutes after premedication with $10 \mathrm{mg} / \mathrm{kg}$ IM xylazine HCL (Rompun, Bayer; İstanbul, Turkey). The skin over both Achilles tendons was shaved and disinfected with povidone-iodine (Betadine, Drogsan; Ankara, Turkey), followed by a $2 \mathrm{~cm}$ incision beginning from the distal insertion of the tendon. Following incision of the paratenon longitudinally, the tendon was cut horizontally $1.5 \mathrm{~cm}$ from the calcaneal insertion. Immediately thereafter, all tendons were primarily repaired via modified Kessler sutures using no. 4/0 PDS.

The rabbits were then randomly divided into two groups. In group A (7 rabbits, 14 tendons), after suturing the paratenon

TABLE 1. Platelet counts in both groups in the collected blood samples and PRP

\begin{tabular}{lccc}
\hline & A & B & p value \\
\hline $\begin{array}{l}\text { Platelet count at the } \\
\text { beginning (number } / \mu \mathrm{L})\end{array}$ & $394 \pm 71$ & $413 \pm 94$ & 0.623 \\
$\begin{array}{l}\text { Platelet count in PRP } \\
\text { (number/ } \mu \mathrm{L})\end{array}$ & $1352 \pm 562$ & $1586 \pm 423$ & 0.465 \\
\hline PRP: platelet rich plasma & & &
\end{tabular}

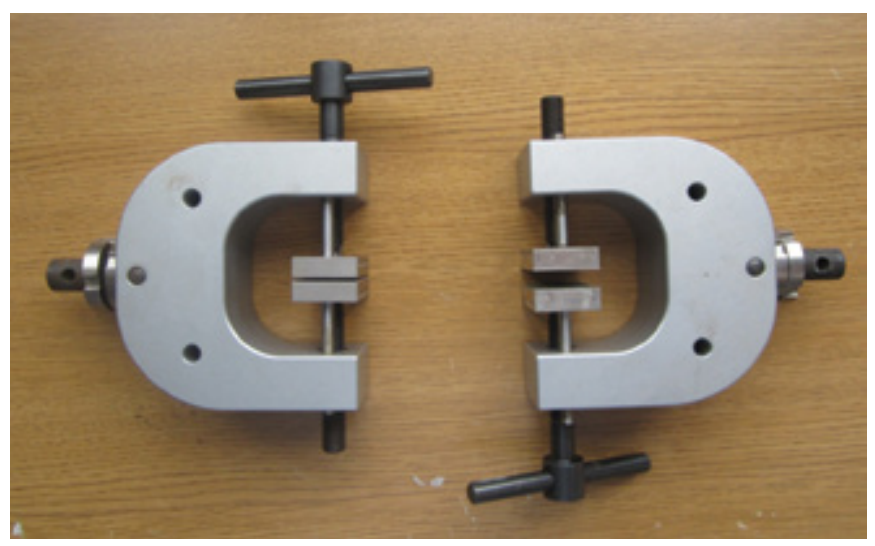

FIG. 1. Specially designed clamps for biomechanical testing 
with 4/0 vicryl, PRP was injected onto the repaired tendon, under the paratenon, and the skin was closed using no. 4/0 propylene. In Group B (7 rabbits, 14 tendons), the paratenon and skin were closed, without injecting PRP onto the repaired tendons. Post-surgery, the rabbits were housed in individual cages $(66 \mathrm{~cm} \times 72 \mathrm{~cm} \times 47 \mathrm{~cm})$, were free to move, and had access to food and water. Antibiotic prophylaxis was not used. Wound care was performed at 2-day intervals using povidoneiodine (Betadine, Drogsan; Ankara, Turkey).

The right leg of each rabbit in both groups was evaluated histopathologically, whereas each left leg was evaluated biomechanically.

On day 28 , the rabbits in both groups were sacrificed under general anesthesia induced via IM injection of $10 \mathrm{mg} / \mathrm{kg}$ xylazine HCL (Rompun, Bayer; İstanbul, Turkey) and $40 \mathrm{mg} / \mathrm{kg}$ IM ketamine (Ketalar, Eczacıbaş1; İstanbul, Turkey), followed by intracardiac infusion of 5 cc of $7.5 \%$ KCL (Basel Kimya; İstanbul, Turkey) via an intravenous catheter needle (Medflon Eastern Medikit Ltd.; Delhi, India).

After sacrifice, the incisions were re-opened, and the tendons and paratenon were excised including the calcaneus distally and the musculotendinous junction proximally, avoiding damage to the healing tissue.

The right Achilles tendons from both groups were split longitudinally into two equal pieces; one was sent to the pathology department in 10\% formalin for light microscopic examination and one was sent to the histology and embryology department in glutaraldehyde for electron microscopic examination. The left tendons from both groups were fixed in $10 \%$ formalin and subjected to biomechanical testing.

\section{Histopathologic evaluation}

\section{Light microscopy}

The samples were embedded in paraffin post-tissue processing and the paraffin blocks were cut into serial $5 \mu \mathrm{m}$ sections. The sections were stained with hematoxylin and eosin (H\&E) and were evaluated under a light microscope by a blinded pathologist, according to Tang's tendon healing scale (35, Table 2). For each sample, four sections were examined and the mean value was calculated.

\section{Transmission electron microscopy}

Samples were immediately fixed in $2 \%$ paraformaldehyde plus glutaraldehyde in $0.1 \mathrm{M}$ sodium phosphate buffer $(\mathrm{pH}$ 7.4), and then stored at $4^{\circ} \mathrm{C}$ for 24 hours. The samples were post-fixed with osmium tetroxide in $0.1 \mathrm{M}$ sodium phosphate buffer for 90 minutes at room temperature, and were subsequently contrasted with $0.5 \%$ uranyl acetate in $70 \%$ acetone and $1 \%$ phosphotungstic acid overnight at $4{ }^{\circ} \mathrm{C}$. The tissues
TABLE 2. Tang tendon healing scale

\begin{tabular}{ll}
\hline Tendon healing scale & $\begin{array}{l}\text { Continuity of tendon is well established; } \\
\text { the epitenon is smooth } \\
\text { The intratendinous collagenous bundles } \\
\text { healed well; but the epitenon had been } \\
\text { destroyed by adhesions }\end{array}$ \\
Good & $\begin{array}{l}\text { The intratendinous collagenous bundles } \\
\text { are irregularly arranged and partly inter- } \\
\text { rupted by adhesions }\end{array}$ \\
Fair & $\begin{array}{l}\text { Disconnection of the repair site or repair } \\
\text { site is connected to a large extent by } \\
\text { granulation or adhesion tissues }\end{array}$ \\
&
\end{tabular}



FIG. 2. Group A. Fibrosis, foreign body multinuclear giant cells, lymphocyte and polymorph nuclear leucocytes (PNLs) containing inflammation, H\&E, X200 (Tang Phase 3)

were processed using routine procedures and embedded in araldite. After semi-thin sections were taken with an ultratome (Leica Microsystems; Wetzlar, Germany), ultrathin $(<0.1 \mu \mathrm{m})$ sections were mounted on grids and analyzed using a transmission electron microscope (TEM, Carl Zeiss Libra 120 EFTEM; Stuttgart, Germany).

\section{Histomorphometry}

Digital image analysis software (UTHSCSA ImageTool v.3.0; San Antonio, TX, USA) was used for image processing. The diameter of each collagen band was measured from transverse sections. Morphometric measurements were compared between the two groups.

\section{Biomechanical testing}

The Biomechanics Laboratory of the institute was used for biomechanical tests and the tendons were subjected to tensile testing in an axial tensile testing machine (AG-I $10 \mathrm{Kn}$; Shimadzu, Japan) using specially designed clamps (Figure 1). 
TABLE 3. Histological scores of the tendons according to Tang's scale

\begin{tabular}{lcc}
\hline Groups & Tendon number & Tang's scale \\
\hline Group A & 1 & 4 \\
& 2 & 4 \\
3 & 3 \\
4 & 4 \\
Group B & 5 & 4 \\
& 6 & 3 \\
& 7 & 3 \\
& 8 & 4 \\
9 & 2 \\
10 & 4 \\
& 11 & 2 \\
12 & 3 \\
& 13 & 3 \\
14 & 3
\end{tabular}

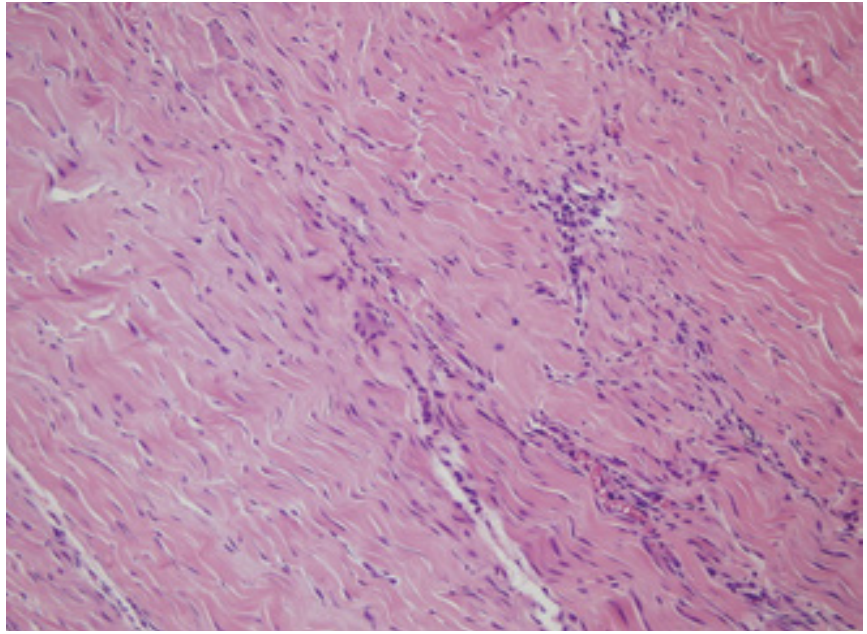

FIG. 3. Group B. Fibrosis, foreign body multinuclear giant cells, lymphocyte and polymorph nuclear leucocytes (PNLs) containing inflammation, H\&E, X200 (Tang Phase 3)

After performing preload at $1 \mathrm{~N}$, in order to not cause a rupture in the healing or adjacent tissue, each tendon underwent tensile testing with a loading speed of $10 \mathrm{~mm} / \mathrm{min}$ until failure.

The process was continued until the tendon-tendon complex broke down at any point. The maximum tensile strength and stiffness values were recorded.

\section{Statistical analysis}

Data were analyzed using SPSS v.11.0 for Windows (SPSS Inc. Released 2003. SPSS for Windows, Version 11.0; Chicago, IL, USA). The non-parametric Mann-Whitney U test was used to detect any statistically significant differences in electron microscopy, histomorphometry, and biomechanical test findings between the two groups, and the chi-square test was used to detect any statistically significant differences in light microscopy findings. The level of statistical significance was set at $\mathrm{p}<0.05$.

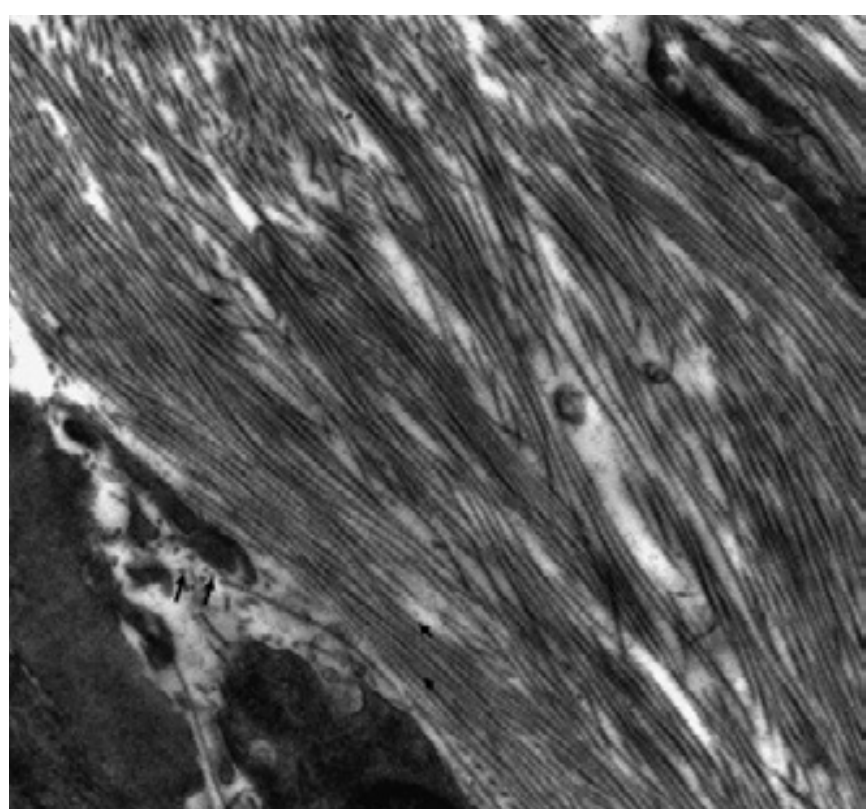

FIG. 4. Microphotograph of a sample from group A shows the tendon cell and transverse (arrows)/longitudinal (arrowheads) collagen bundles ( ${ }^{*}$ : nucleus) X5000.

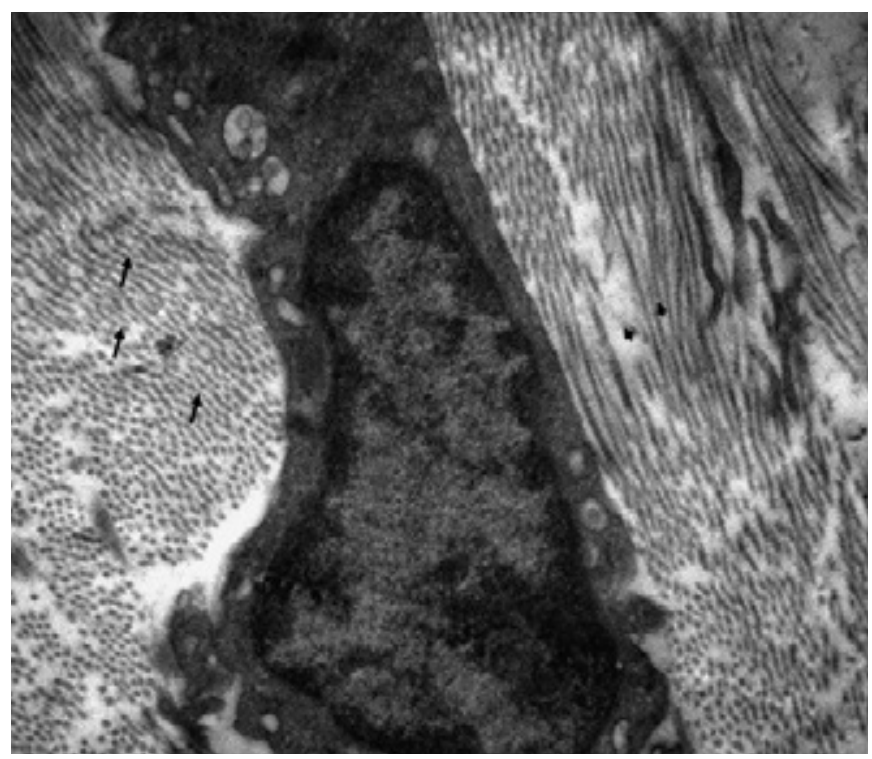

FIG. 5. Microphotograph of a sample from group B shows the tendon cell and transverse (arrows)/longitudinal (arrowheads) collagen bundles ( ${ }^{*}$ : nucleus) X5000.

\section{RESULTS}

All rabbits were kept comfortable, at a convenient room temperature, and no infection was observed at the operation site.

\section{Light microscopy results}

The histological scores of the tendons based on Tang's scale are shown in Table 3. Although group A scores were better 


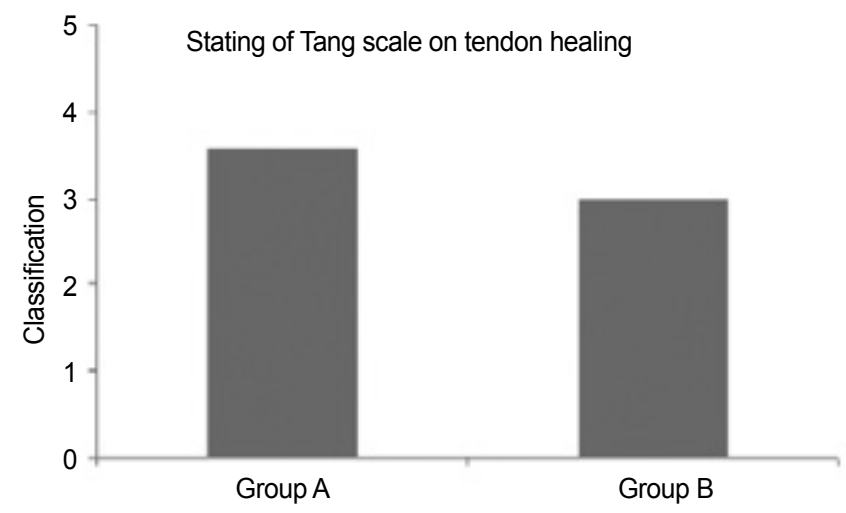

FIG. 6. Comparison of the groups according to Tang's scale

Histomorphometry (Dimension of Collagen measurements

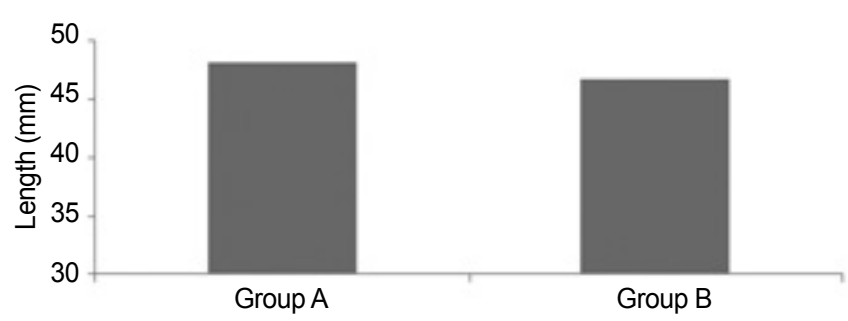

FIG. 7. Diameters of transverse sections of collagen fibers

(Mean value in Group A: 3.7, Group B: 3.0), there was no significant difference between the two groups. A comparison of Tang's scale scores between the two groups is shown in Figure 6. The histological appearance of a sample from each group is shown in Figures 2 and 3.

\section{Electron microscopy results}

\section{Fine structure findings}

Both groups were evaluated in terms of fine structure based on microphotographs. The nucleus and organelles of the tendon cells were determined to be structurally normal; the difference between groups was not significant. The mean value of Group A among the length of collagen bands was $48.09 \mathrm{~nm}$ while the mean value of Group B was $46.58 \mathrm{~nm}(\mathrm{p}=0.406)$ (Figure 7). Microphotographs from each group are shown in Figures 4 and 5.

\section{Biomechanical findings}

Although stiffness values were higher in group A, the difference between groups was not significant (Figure 8). In addition, maximum load values did not differ between groups $\mathrm{A}$ and B (Figure 9).

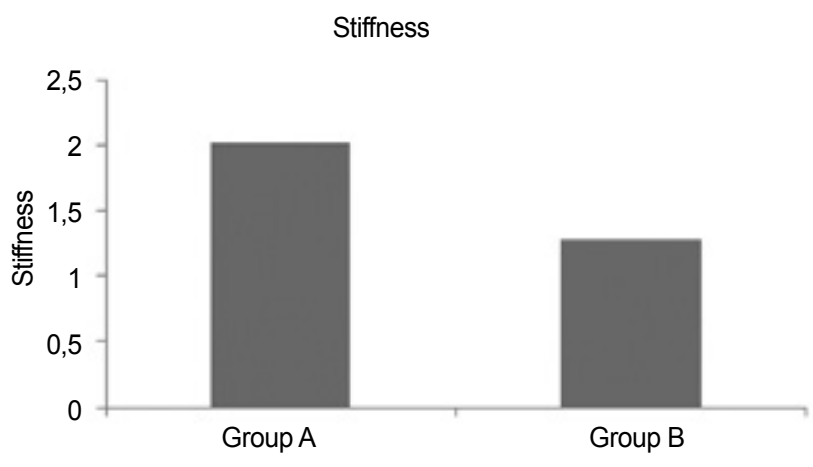

FIG. 8. Comparison of stiffness measurements between the groups

Maximum Force

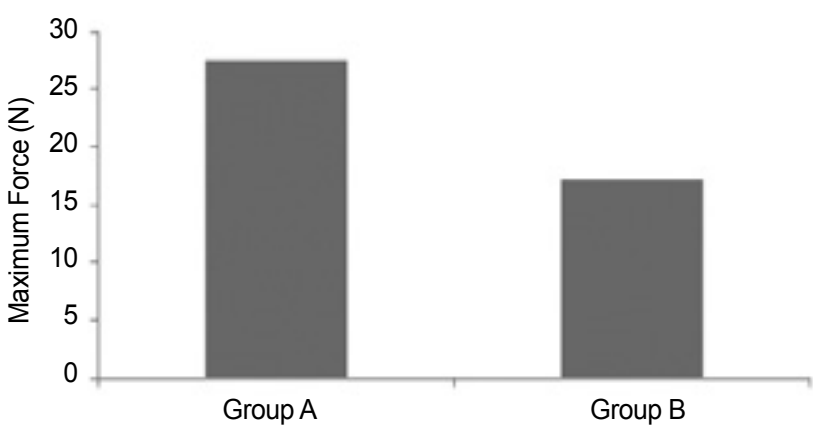

FIG. 9. Comparison of maximum load measurements between the groups

\section{DISCUSSION}

The present experimental study aimed to determine both the histopathological and biomechanical aspects of the effect of PRP on Achilles tendon healing post rupture. To the best of our knowledge, PRP (a biomaterial with potentially beneficial effects on the healing of almost every tissue) has been previously studied in terms of the histopathology and biomechanics of Achilles tendon ruptures (25-28), but the present study is the first to use autologous PRP and electron microscopic evaluation.

Kajikawa and Aspenberg $(21,25)$ used donor rats and sacrificed them after collecting their blood and injecting the derived PRP into other rats. Rabbits were used in the present study because we wanted to use autologous blood and PRP. We think that rabbits are more suitable than rats for such research. To the best of our knowledge, the present experimental study is the first to examine tendon healing and PRP obtained via autologous blood.

The literature does include some clinical and experimental studies on the effect of PRP on tendon healing (1-3,21-32). As PRP contains growth factors, it is rational to include an examination of research on growth factors in the present discussion. 
Jelinsky et al. (19) reported that rhBMP12 and rhBMP13 accelerated the speed of Achilles tendon repair in a rat model, as reported in other BMP studies $(15,16,36)$. Zhang et al. (17) reported the promising effect of vascular endothelial growth factor on rat Achilles tendon repair. Despite these positive findings, Konerding et al. (2) studied the effect of short-term application of a combination of growth factors on tendon healing in cases of conservative and operative treatment, and reported that the use of growth factor did not result in a significant biomechanical or histological improvement in collagen type ratios.

Nonetheless, we think that growth factors have a positive effect on tendon healing, as mentioned above, but they are expensive and difficult to obtain, and their production requires advanced laboratory conditions and technology, which is why their use in routine clinical treatment remains limited. Additionally, the use of PRP might be considered a more rational approach than use of individual or combinations of growth factors, as it contains all growth factors.

Most experimental studies on PRP and tendons report positive findings. Aspenberg and Virchenko (25) reported the positive effect of platelet concentrate on Achilles tendon healing in rats based on biomechanical testing, as confirmed via histological scoring. They observed improvements in maximum stress as much as $21 \mathrm{~d}$ and $28 \mathrm{~d}$ post-injury. Their findings were confirmed by Anitua et al. (37), who studied tendon cell cultures. Kajikawa et al. (21) used PRP during the early phase of patellar tendon healing in rats and reported that locally injected PRP was a useful activator of circulation-derived cells for enhancement of the initial tendon healing process.

According to Lyras et al. (23), PRP stimulates vascularization and tissue organization in rabbit Achilles tendons. Kaux et al. (27) histologically and biomechanically examined repaired rat tendons, and concluded that mechanical resistance was significantly higher in the tendons in the PRP group on $\mathrm{d} 30$ post-injury.

Clinical studies on PRP and tendons are fewer in number than experimental studies and the findings are inconsistent. Sanchez et al. (1) used PRP fibrin matrices in 12 athletes with Achilles tendon rupture in a case-control study. They reported that the athletes treated with PRP had better range of motion and returned to sport training sooner than those in the control group. Unfortunately, Schepull et al. (3) conducted a randomized clinical trial and concluded that PRP was not useful in the treatment of Achilles tendon ruptures, as there was no difference in the heel raise index and Achilles Tendon Total Rupture Score between those treated with PRP and those that were not. Moreover, they reported that PRP had a negative effect on tendon healing. In some other recent retrospective and prospective clinical studies, the same results were obtained, showing that adding PRP to the treatment regimen was not clinically and functionally superior $(31,32)$.
In contrast to earlier experimental studies, there was no significant difference in the histopathological and biomechanical evaluation findings between the two groups in the present study, which may have been because of the small number of animals studied. More significant findings might be obtainable using a larger study group, but ethical considerations limited the number of rabbits in each group to seven, which is considered a limitation of the study. The result of this experimental study cannot influence the use of PRP in daily practice, mostly because of the different results of the material when compared to the clinical studies on human beings.

According to Lui et al. (38), cell number decreases to restore the normal cell-to-matrix ratio at the late stage of tendon healing in rats. The researchers reported that this finding was due to apoptosis during the late phase of tendon healing, with a maximum value 28 days post-injury. This finding was confirmed by other studies $(39,40)$, suggesting that tendon strength decreases in most cases after the $28^{\text {th }}$ day post-injury, which is why the tendons were examined 28 days post-injury in the present study.

Sasaki et al. (41) evaluated the Achilles tendon in rats via electron microscopy and reported that it was useful for visualizing the 3-dimensional network of collagen fibers, especially during the first 28 days post-injury, which is another reason why tendons in the present study were evaluated 28 days post-injury. We think that electron microscopy is the best tool for the evaluation of tendon structure, in terms of morphometric measurement and objective findings, as reported by Hazard et al. (42).

In conclusion, although our results showed some differences between the PRP-injected and control groups, these differences were not statistically significant. Future studies with sample sizes adequate to look for significant differences should be considered. However, it can be stated that PRP did not significantly affect the healing process in Achilles tendon ruptures in a rabbit model 28 days post-injury.

Ethics Committee Approval: Ethics committee approval was received for this study from the Local Animal Research Ethics Committee.

\section{Informed Consent: N/A.}

Peer-review: Externally peer-reviewed.

Author contributions: Concept - H.T.; Design - B.Ş., S.G.; Supervision - H.T.; Resource - B.Ç., E.K.; Materials - S.G.; Data Collection \&/or Processing - B.Ş., M.A.Ö.; Analysis \&/or Interpretation - A.B., S.Ö., N.Ş.; Literature Search - B.Ş., H.T.; Writing - B.Ş., H.T.; Critical Reviews - H.T., H.Ö.

Conflict of Interest: No conflict of interest was declared by the authors. 
Financial Disclosure: The authors declared that this study has received no financial support.

\section{REFERENCES}

1. Sanchez M, Anitua E, Azofra J, Andia I, Padilla S, Mujika I. Comparison of surgically repaired Achilles tendon tears using plateletrich fibrin matrices. Am J Sports Med 2007;35:245-51. [CrossRef]

2. Konerding MA, Friederike A, Wellmann A, Li V, Li W. Impact of combinatory growth factor application on rabbit Achiles tendon injury with operative versus conservative treatment: A pilot study. Int J Mol Med 2010;25:217-24.

3. Schepull T, Kvist J, Norrman H, Trinks M, Berlin G, Aspenberg P. Autologous platelets have no effect on the healing of human Achilles tendon ruptures. Am J Sports Med 2011;39:39-47. [CrossRef]

4. Khan RJ, Fick D, Keogh A, Crawford J, Brammar T, Parker M. Treatment of acute Achilles tendon rupture. A meta-analysis of randomized controllod trials. J Bone Joint Surgery Am 2005;87:2202-10. [CrossRef]

5. Halıcı M, Karaoğlu S, Canöz O, Kabak Ş, Baktır A. Sodium hyaluronate regulating angiogenesis during Achilles tendon healing. Knee Surg Sports Traumatol Arthrosc 2004;12:562-7. [CrossRef]

6. Petrou CG, Karachalios TS, Khaldi L, Katantanas AH, Lyritis GP. Calsitonin effect on Achilles tendon healing: An experimental study on rabbits. $J$ Musculoskelet Neuronal Interact 2009;9:147-54.

7. Leek BT, Tasto JP, Tibor LM, Healey RM, Freemont A, Linn MS, et al. Augmentation of tendon healing with butyric acid impregnated sutures: Biomechanical evaluation in a rabbit model. Am J Sports Med 2012;40:1762-71. [CrossRef]

8. Çoban İ, Satoğlu S, Gültekin A, Tuna B, Tatari H, Fidan M. Effect of human amniotic fluid and membrane in the treatment of Achilles tendon ruptures in locally corticosteroid-induced Achilles tendinosis: An experimental study on rats. Foot Ankle Surg 2009; 15:22-7. [CrossRef]

9. Malcarney HL, Bonar F, Murrell GA. Early inflammatory reaction after rotator cuff repair with a porcine small intestine submucosal implant: a report of 4 cases. Am J Sports Med 2005;33: 907-11. [CrossRef]

10. Zheng MH, Chen J, Kirilak Y, Willers C, Xu J, Wood D. Porcine small intestine submucosa (SIS) is not an acellular collagenous matrix and contains porcine DNA: Possible implications in human implantation. J Biomed Mater Res B Applied Biomater 2005;73:61-7. [CrossRef]

11. Nicholson GP, Breur GJ, Sickle DV, Yao JQ, Kim J, Blanchard CR. Evaluation of a cross-linked acellular porcine dermal patch for rotator cuff repair augmentation in an ovine model. J Shoulder Elbow Surg 2007;16:184-90. [CrossRef]

12. Badhe SP, Lawrence TM, Smith FD, Lunn PG. An assessment of porcine dermal xenograft as an augmentation graft in the treatment of extensive rotator cuff tears. J Shoulder Elbow Surg 2008;17:35-9. [CrossRef]
13. Sarrafian TL, Wang H, Hackett ES, Yao JQ, Shih MS, Ramsay $\mathrm{HL}$, et al. Comparison of Achilles tendon repair techniques in a sheep model using a cross-linked acellular porcine dermal patch and platelet-rich fibrin matrix for augmentation. J Foot Ankle Surg 2010;49:128-34. [CrossRef]

14. Lee DK. Achilles tendon repair with acellular tissue graft augmentation in neglected ruptures. J Foot Ankle Surg 2007;46:4515. [CrossRef]

15. Bolt P, Clerk AN, Luu HH, Kang Q, Kummer JL, Deng ZL. BMP-14 gene therapy increases tendon tensile strength in a rat model of Achilles tendon injury. $J$ Bone Joint Surg Am 2007;89:1315-20. [CrossRef]

16. Forslund $\mathrm{C}$, Aspenberg P. Improved healing of transected rabbit Achilles tendon after a single injection of cartilage-derived morphogenetic protein-2. Am J Sports Med 2003;31:555-9.

17. Zhang F, Liu H, Stile F, Lei MP, Pang Y, Oswald TM, et al. Effect of vascular endothelial growth factor on rat Achilles tendon healing. Plast Reconstr Surg 2003;112:1613-9. [CrossRef]

18. Taylor DW, Petrera M, Hendry M, Theodoropoulos JS. A systematic review of the use of platelet-rich plasma in sports medicine as a new treatment for tendon and ligament injuries. Clin J Sports Med 2011;21:344-52. [CrossRef]

19. Jelinsky SA, Li L, Ellis D, Archambault J, Li J, St Andre M. Treatment with rhBMP12 or rhBMP13 increase the rate and the quality of rat Achilles tendon repair. J Othop Res 2011;29:160412. [CrossRef]

20. Paoloni J, de Vos RJ, Hamilton B, Murrell GAC, Orchard J. Platelet-rich plasma treatment for ligament and tendon injuries. Clin J Sports Med 2011;21:37-45. [CrossRef]

21. Kajikawa Y, Morihara T, Sakamoto H, Matsuda K, Oshima Y, Yoshida A, et al. Platelet-rich plasma enhances the initial mobilization of circulation-derived cells for tendon healing. J Cell Physiol 2008;215:837-45. [CrossRef]

22. Kim HJ, Kang SW, Lim HC, Han SB, Lee JS, Prasad L. The role of Transforming Growth Factor- $\beta$ and bone morphogenetic protein with fibrin glue in healing of bone-tendon junction injury. Connect Tissue Res 2007;48:309-15. [CrossRef]

23. Lyras DN, Kazakos K, Verettas D, Polychronidis A, Tryfonidis $\mathrm{M}$, Botaitis S, et al. The influence of platelet-rich plasma on angiogenesis during the early phase of tendon healing. Foot Ankle Int 2009;30:1101-6. [CrossRef]

24. Lyras DN, Kazakos K, Tryfonidis M, Agrogiannis G, Botaitis S, Kokka A, et al. Temporal and spatial expression of TGF - $\beta 1$ in an Achilles tendon section model after application of plateletrich plasma. Foot Ankle Surg 2007;16:137-41. [CrossRef]

25. Aspenberg $\mathrm{P}$, Virchenko O. Platelet concentrate injection improves Achilles tendon repair in rats. Acta Orthop Scand 2004;75:93-9. [CrossRef]

26. Virchenko O, Aspenberg P. How can one platelet injection after tendon injury lead to a stronger tendon after 4 weeks? Acta Orthop 2006;77:806-12. [CrossRef]

27. Kaux JF, Drion PV, Colige A, Pascon F, Libertiaux V, Hoffmann A. Effects of platelet-rich plasma (PRP) on the healing of Ac- 
hilles tendons of rats. Wound Repair Regen 2012;20:748-56. [CrossRef]

28. Xu K, Al-Ani MK, Sun Y, Xu W, Pan L, Song Y, et al. Plateletrich plasma activates tendon derived stem cells to promote regeneration of Achilles tendon rupture in rats. J Tissue Eng Regen Med 2015 (article in press). [CrossRef]

29. De Vos RJ, Weir A, Tol JL, Verhaar JAN, Weinans H, van Schie HTM. No effects of PRP on ultrasonographic tendon structure and neovascularization in chronic midportion Achilles tendinopathy. Br J Sports Med 2011;45:387-92. [CrossRef]

30. De Vos RJ, Weir A, van Schie HT, Bierma-Zeinstra SM, Verhaar JA, Weinans H. Platelet-rich plasma injection for chronic Achilles tendinopathy: a randomized controlled trial. JAMA 2010;303:144-9. [CrossRef]

31. Kaniki N, Willits K, Mohtadi NG, Fung V, Bryant D. A retrospective comparative study with historical control to determine the effectiveness of platelet rich plasma as art of nonoperative treatment of acute achilles tendon rupture. Arthroscopy 2014;30:1139-45. [CrossRef]

32. De Carli A, Lanzetti RM, Ciompi A, Lupariello D, Vadala A, Argento G. Can platelet-rich plasma have a a role in Achilles tendon surgical repair? Knee Surg Sports Traumatol Arthrosc 2015 (online article).

33. Yokota K, Ishida O, Sunagawa T, Suzuki O, Nakamae A, Ochi M. Platelet-rich plasma accelerated surgical angio-genesis in vascular-implanted necrotic bone: An experimental study in rabbits. Acta Orthop 2008;79:106-10. [CrossRef]

34. Efeoglu, C, Akcay YD, Erturk S. A modified method for preparing platelet-rich plasma: An experimental study. J Oral Maxillofac Surg 2004;62:1403-7. [CrossRef]
35. Tang J, Ishii S, Usui M, Aoki M. Dorsal and circumferential sheath reconstructions for flexor sheath defect with concomitant bony injury. J Hand Surg 1994;19:61-9. [CrossRef]

36. Kurtz CA, Loebig TG, Anderson DD, DeMeo PJ, Campbell PG. Insulin-like growth factor I accelarates functional recovery from Achilles tendon injury in a rat model. Am J Sports Med 1999;27:363-9.

37. Anitua E, Andia I, Sanchez M, Azofra J, del Mar Zalduendo M, de la Fuente M, et al. Autologous preparations rich in growth factors promote proliferation and induce VEGF and HGF production by human tendon cells in culture. J Orthop Res 2005;23:281-6. [CrossRef]

38. Lui PPY, Cheuk YC, Hung LK, Fu SC, Chan KM. Increased apoptosis at the late stage of tendon healing. Wound Repair Regen 2007;15:702-7. [CrossRef]

39. Mae T, Shino K, Maeda A, Toritsuka Y, Horibe S, Ochi T. Effect of gamma irradiation on remodeling process of tendon allograft. Clin Orthop Relat Res 2003;414:305-14. [CrossRef]

40. Steiner M. Biomechanics of tendon healing. $J$ Biomech 1982;15:951-8. [CrossRef]

41. Sasaki K, Yamamoto N, Kiyosawa T, Sekido M. The role of collagen arrangement change during tendon healing demonstrated by scanning electron microscopy. J Electron Microsc (Tokyo) 2012;61:327-34. [CrossRef]

42. Hazard SW, Myers RL, Ehrlich HP. Demonstrating collagen tendon fibril segments involvement in intrinsic tendon repair. Exp Mol Pathol 2011;91:660-3. 